\title{
YouTube: An Effective Web 2.0 Informing Channel for Health Education to Prevent STDs
}

\author{
Gayle Prybutok \\ University of North Texas, Denton, Texas, USA
}

GaylePrybutok@my.unt.edu

\begin{abstract}
YouTube is a social media venue with great potential as a health education-informing channel. Health educators and the Centers for Disease Control and Prevention (CDC) (2011) recognize that YouTube enjoys a high level of engagement and comfort among young users. This enhances its educational value for this vulnerable population, who already account for half of the new sexually transmitted diseases (STDs) diagnosed annually. It is imperative to reach these users with information about safe sex and sexual risk prevention. In this work, 18-24 year old undergraduates were pre-tested, and half of the participants viewed an entertaining YouTube safe sex education video while the other half viewed a factual YouTube safe sex education video. Posttests on both groups confirmed YouTube's significant value as a health education-informing channel that fosters knowledge acquisition and provokes healthy future behavior change. This study clarifies user preferences for health education messaging on YouTube, and confirms YouTube's substantial educational utility, while guiding health educators' effective use of this health education-informing channel.
\end{abstract}

Keywords: YouTube, health-informing channel, information seeking behavior, social media

\section{Introduction}

The successful delivery of accurate, timely, and relevant health information that promotes knowledge acquisition and behavior change in targeted populations is a primary goal for public health educators (Valencia, Kingston, Nakamura, Rosenfield, \& Schwartz, 2004). Health educators have recently identified social media as viable health-informing channel for young adults, ages 18-24 (Centers for Disease Control and Prevention [CDC], 2011). These users are already using YouTube and other social media venues for entertainment, social engagement, relaxation, and information exchange (Hordemann \& Chao, 2012; Jones \& Fox, 2009). Health educators must determine if these users view YouTube and its associated video content as a viable healthinforming channel. This study seeks to answer two research questions. First, this work will test whether or not YouTube, an Internet based social media informing channel, can deliver safe sex/condom use information designed to facilitate knowledge acquisition in a population of 18-24

Material published as part of this publication, either on-line or in print, is copyrighted by the Informing Science Institute. Permission to make digital or paper copy of part or all of these works for personal or classroom use is granted without fee provided that the copies are not made or distributed for profit or commercial advantage AND that copies 1) bear this notice in full and 2) give the full citation on the first page. It is permissible to abstract these works so long as credit is given. To copy in all other cases or to republish or to post on a server or to redistribute to lists requires specific permission and payment of a fee. Contact Publisher@InformingScience.org to request redistribution permission. year old users. Second, this work assesses whether an entertaining or factual message delivery format for the same content results in a different level of knowledge acquisition.

In the 2010 Centers for Disease Control and Prevention (CDC) Sexually Transmitted Disease Surveillance Report (CDC, 2010), the CDC revealed that there are an estimated 19 million new 
sexually transmitted disease (STD) infections each year. The financial impact to the United States' healthcare system is $\$ 17$ billion per year, and STDs bring immediate and lifelong consequences to infected individuals. "Young people represent $25 \%$ of the sexually experienced population in the United States, but account for nearly half of new STDs" (CDC, 2010, p. 1). Clearly, 18-24 year old users can benefit from education about safe sex. Yet often, this at risk population does not intentionally seek information about safe sex (Singhai \& Rogers, 2002). This is true for several reasons. First, the media often casts sexual activity as spontaneous and unplanned $(\mathrm{Yu}$, 2010), which is not consistent with seeking information. Also, as young, healthy adults, people this age do not usually consider themselves at risk. They frequently have no interest in learning about risks associated with unprotected sex, or if sexually active, might use a form of birth control that does not include a barrier because they are not cognizant of the associated health risks (Singhai \& Rogers, 2002).

The purpose of this study is to test the viability of using YouTube as a health-informing channel to facilitate knowledge acquisition about safe sex/condom use for young adults, ages 18 to 24 . The study specifically examines two issues: the viability of using YouTube as an informing channel for health education, and the differences in 18-24 year old viewer knowledge acquisition based on the type of YouTube safe sex video message (factual vs. entertaining) provided. Arroyave (2008) reported that Education Entertainment (E-E) is defined as intentionally embedding important health information in a media message in order to educate viewers and encourage risk reduction or disease prevention behaviors. Arroyave reported that E-E does this successfully in the United States and in over 50 other countries. Both factual and entertaining message formats deliver relevant and memorable information aimed at provoking healthy sexual behaviors. It is important to examine and quantify whether users in this age group absorb and retain the same health education content presented on YouTube, and whether retention differences exist based on an entertaining message delivery format or a factual one. The data collected in this study will help health educators to present important information successfully about health maintenance and disease prevention using a message delivery format and social media venue that most effectively engages 18-24 year old users. This study will also help to quantify which message delivery format best facilitates knowledge acquisition, retention and future healthy behavior change. A study by Smith, Nazione, Laplante, Kotowski, Atkin, Skubisz and Stohl (2009) has already demonstrated that a memorable message, even if not acted upon immediately, can result in a behavior change when remembered.

\section{Literature Review}

\section{The Internet as an Informing Channel}

In 1995, Everett Rogers, in Diffusion of Innovations (4th edition), stated that diffusion of innovation is the "process by which innovation (or communication about new ideas) is transmitted through channels from one person to another in a social group, over a period of time" (p.5). Rogers coined the term "communication channel", defining it as "the means by which messages get from one individual to another" (p.18). He described two types of information channels: mass media channels and interpersonal channels. Mass media channels, like newspapers, radio, and $\mathrm{TV}$, allow one source of information to reach many people at the same time and are fast and efficient. Interpersonal communication channels are rooted in the interactions between people and, while less efficient, are often more persuasive. Bargh and McKenna (2004) stated that "the Internet affords a new and different avenue of social interaction that enables groups and relationships to form that otherwise would not be able to, thereby increasing and enhancing social connectivity" (p.575). The Internet and its associated social media sites offer an ideal blend of Rogers' 
two communication channels, providing both the broad reach of mass media information channels and the personal interaction typical of interpersonal communication channels.

Informing science was defined by Cohen (2009) as a "transdiscipline that explores how best to inform clients using information technology" (p 1). Hardin, Ryan and Prybutok (2012) extended the application of Cohen's work and suggested that an informing system had three components: "the informing environment, the delivery system, and the task completion system" (p.207). They identified social media as an information delivery system or informing channel for both personal and professional communications.

\section{Internet Use Statistics}

The Pew Research Center's Internet and American Life Project, funded in 2000, evaluates the impact of Internet use in the United States, and produces a number of targeted reports each year (Pew Internet and American Life Project, n.d.). In 2010, a report by Baumann showed that 74\% of Americans use the Internet. The May 2010 Pew Research Center Tracking Survey reported that $95 \%$ of 18 to 29 year olds use the Internet (Pew Internet and American Life Project, 2010). Greenwood (2009) also found that more than 50\% of active Internet users are between 18 and 24 years of age. These statistics reveal the potential of the Internet and, particularly, of interactive Web 2.0 venues to provide important health information capable of encouraging risk management and disease prevention behaviors in users ages 18 to 24 .

\section{The Internet as a Health Informing Channel}

With the advent of Web 2.0, Internet users of all ages became more likely to seek health information on the Internet because information on the Web is easy to access and provides anonymity when the information need is highly personal (L. Luo, 2010). Prior to development of the World Wide Web, people relied on family doctors when they needed health information or advice. When they realized that health information was conveniently available on the Internet, they initially explored sites with "URL's ending in .edu, .net, .com or.org" (J. S. Luo, 2008, p.24) because they believed that the information on these sites was most credible. As users gained experience with Internet based health information, they recognized the Internet as a cost effective healthinforming channel, available 24/7. Users relied on it as a valuable aid in health care decisionmaking that allowed them to actively participate in their own healthcare (Suggs, 2006).

Several types of people rely on the Internet for healthcare information. Brashers, Goldsmith, and Hsieh (2002) reported that healthy people seek health information that reassures them of their wellness, while the sick look for information about their specific illness, treatment choices and the expected course of their infirmities. Abrahamson, Fisher, Turner, Durrance, and Turner (2008) proposed a third type of person that seeks health information on the Internet: "Lay information mediaries seek information on behalf or because of others without necessarily being asked to do so, or engaging in follow up" (p. 310).

Many health information seekers value the ability to interact via Web 2.0 social media venues. They appreciate the exchange of information with health experts and the dialogue about shared experiences with other people suffering from the same conditions. Weaver, Thompson, Weaver and Hopkins (2009) hailed the interactive nature of Web 2.0 as a new public health venue and Cline and Hayes (2001) determined that interactive health communication, available through social media venues, promotes wellness in the healthy public. Additionally, social media offers an informing channel that supports the sick and offers a valued cluster of communication resources for health care providers who use them to reach targeted groups. 


\section{Social Media on the Internet}

In 2007, Boyd and Ellison defined the parameters of a social media site. They noted that social media sites:

- allow users to create public or semi-public profiles within a closed environment

- permit the user to identify other users with whom they are willing to connect, and prevent undesignated users from viewing the owner's profile and information

- allow the user to view the pages of other users that have given their permission to do so, and facilitate interaction between them.

Social media in this context includes familiar sites like Twitter, MySpace, Facebook, Flickr, and YouTube, and extends to blogs, wikis, and online medical support groups (Kahn, 2008). Rajipat (2009) suggested that social media benefits all users by providing an equal opportunity to share ideas and opinions, and Scale (2008) noted that these venues have the ability to make users feel secure while sharing highly personal information. Choi, Kim, Sung and Sohn (2011) pointed out that users have become quite comfortable with online discourse because social media and Internet use have become important components of users' daily routines. Kahn (2008) noted the ability of users to interact both with information and with other users by exchanging videos and textual messages, participating in blogs and social networks, sharing recorded materials, and joining online communities. In 2010, Madden determined that $65 \%$ of adults online in the United States reacted positively to social networking. Chou, Hunt, Beckjord, Moser, and Hesse (2009) pointed out that social networks reach users in spite of differences in ethnicity, race, educational background, and geographical location. For these reasons, social media sites have multiplied exponentially. L. Liu's 2010 study showed that the three most often used social media sites were Wikipedia, YouTube, and Facebook, and the top four reasons for using social media were for "social engagement ...communication, speed of feedback and relationship building" (p.101). Hence, social media venues are informing channels with significant educational potential.

\section{Social Media as a Health Informing Channel}

Chou et al. (2009) view social media venues as ideal mediums for health educators seeking to educate the public and encourage risk management and disease prevention behaviors. Reynolds (2010) reported on the Center for Disease Control's (CDC) implementation of a social media communication campaign during the $\mathrm{H} 1 \mathrm{~N} 1$ crisis several years ago. At that time, public confidence in government organizations was low, and the CDC, in an effort to inform many people rapidly, decided to capitalize on the popularity of social media. They provided essential information about H1N1 using Twitter, MySpace, Facebook, YouTube, and podcasts and delivered simple, honest, and relevant messages during the crisis. A post-crisis public opinion survey, conducted by the American Customer Satisfaction Index, showed an 8\% increase in public satisfaction over the rating in the prior quarter, to a new high of $82 \%$ (Reynolds, 2010). Spurred by this success, the CDC produced the Social Media Toolkit (CDC, 2011), a collection of best practice guidelines for health educators interested in using Facebook, Twitter, text messages, online videos, e-cards, and other materials to educate users and stimulate healthy behavior change.

\section{YouTube as a Health Informing Channel}

Alexa (2011) reported that YouTube, an Internet social media and video viewing site, ranks third in the world for volume of video traffic and enjoys a larger audience of 18 to 24 year olds than other Internet sites. Paek, Kim, and Hove (2010) conducted a content analysis of 934 YouTube antismoking videos and determined that there was significant opportunity available on YouTube to promote health education materials. They also concluded that the interactive nature of this venue was useful not only for the viewing audience, but also for health educators who could use 
viewer comments to evaluate audience response. Dr. William Howe, a University of Colorado dermatologist, used YouTube between 2010 and 2011 to effectively distribute messages about skin cancer prevention to young people (Dawson, Hamstra, Huff, Gamble, Howe, Kane, \& Dellavalle, 2011). Howe chose YouTube for its easy access and because it was the most highly used social network for video viewing (Buzzetto-More, 2012). Keelan, Pavri-Garcia, Tomlinson, and Wilson (2007) conducted a content analysis of YouTube videos about immunization and again saw great potential for YouTube to be an effective health-informing channel.

\section{Education Entertainment}

The benefit of framing an important health education message in an entertainment venue, or Education Entertainment (E-E), is under investigation in the health education literature. In 2006, Jin studied the educational impact of a popular health television program in Korea and found that health E-E programming was "positively associated with overall interest in health issues and perceptions of the severity of personal health problems" (p.79). In other words, it is an effective means of engaging audience members in learning how take better care of themselves.

\section{Are Entertaining or Factual Message Appeals More Effective, and is Learning Affected by the Type of Message Appeal?}

In 2002, Singhai and Rogers studied the mediating effect of entertainment on eHealth education (or Internet based health education). They incorporated a safe sex/condom use presentation made by a physician avatar in a 3D virtual world, Second Life, during the participants' gaming experience. Participants who received eHealth education from the avatar were tested, and they understood and remembered the educational material presented well. Their understanding and recollection was, in part, attributed to the entertaining nature of the presentation. In 2011, MoyerGuse, Mahood, and Brookes also studied the impact of humor on E-E that focused on sexual health. They noted that while a humorous message can increase viewer attention, be more persuasive, and provoke a positive viewer response, it is important to ensure that the important risk prevention message does not become trivial because of the humorous context.

Literature suggests that YouTube can be an effective health informing channel for 18 to 24 year old users and that viewer engagement and learning can be affected by the type of message appeal (factual or entertaining) used in the YouTube video. This study provides data that provides insight on these suggestions.

\section{Methodology}

This work extends the informing science framework to health information delivery by quantifying whether YouTube can deliver safe sex/condom use information and facilitate knowledge acquisition in a population of 18-24 year old users. In addition, this mixed method study will quantify whether an entertaining or factual message delivery format of the same content more effectively fosters knowledge acquisition.

Lopez-Fernandez and Molina-Azorin (2011) state that mixed method studies offer richer results that lead to greater understanding of the issue at hand and facilitate new ideas in a way that cannot be achieved by either quantitative or qualitative methods alone. This study relies on pre- and post-test measures (Rosner, 2011) and a quantitative survey to assess knowledge acquisition about STD prevention. Then, the investigator used a qualitative, open-ended question to collect specific feedback about participant response to each type of STD message presentation style (factual vs. entertaining). 
For this study, the investigator recruited 33 student participants from an undergraduate business course at the University of North Texas. Participants needed to be between the ages of 18 and 24 to participate. Participants signed informed consent forms during the recruitment session and understood that they would participate in a study about safe sex. The investigator assigned participants to one of the two study groups (factual or entertaining safe sex video) via randomization of the signed informed consent forms that the participants provided. The investigator subsequently emailed each participant a link to the appropriate survey version, based on this random assignment.

Using the search term "safe sex", the investigator reviewed available YouTube videos that delivered educational content about the prevention of sexually transmitted diseases. The goal was to identify two tasteful safe sex education videos with the same educational content but with two different message delivery styles, one factual and the other entertaining. The factual video selected was "STD Prevention and Protection (Safe Sex, Sexy Sex \#1)", found at http://youtu.be/mr5ghuaTK14? $\mathrm{t}=5 \mathrm{~s}$. The video was uploaded to YouTube from Healthguru.com, a popular resource library of health, pregnancy, and sex education videos. The available video statistics showed that the video posted on 12/17/07. On the selection date, the video had 26,475,632 views, 13,262 documented likes, and 4824 documented dislikes. Alice W. Ko, MD, from the Department of Obstetrics and Gynecology, Doctors of the World, Johns Hopkins, a world-renowned medical institution, presented information in the video. The video lasts 3 minutes and 8 seconds. The second video selected was an entertaining video entitled "How to Have Safe Sex", found at http://youtu.be/VYNDe_eoJZg?t=6s. Howcast uploaded the video on 2/8/08, and on the selection date had 89,414 views, 122 documented likes, and 26 documented dislikes. Howcast, founded in 2008, is a provider of instructional video content in many topic areas. In this video, the educational content comes through a "voice over" narration to a mimed and comical interaction between two older adults and highlights key points that also appear as text on screen. This video lasts 3 minutes and 20 seconds. Both videos are similar in length, were determined by health educators to share the same educational content, and were professionally made. The investigator created a test based on the safe sex educational content present in both videos. The goals of this study are the following:

(1) to demonstrate that YouTube is viable as a health education-informing channel for 18-24 year old users. To do this, the investigator will measure knowledge acquisition using a pretest and identical posttest.

(2) to identify whether participants acquire a different level of knowledge about safe sex content based on the message delivery style (an entertaining YouTube safe sex video, or the more serious factual alternative).

Hence, the following research hypotheses about the effectiveness of the YouTube safe sex educational videos to promote knowledge acquisition and the difference in mean posttest difference scores between viewers based on the two video message presentation styles (factual or entertaining) were tested.

Hypothesis I states:

H1o: The average difference in the pre- and post-test scores for all participants was less than or equal to 0

H1a: The average difference in the pre- and post-test scores for all participants is greater than 0

Or

H1o: $\mathrm{m}_{\text {Diff (post-pre)t }} \leq 0$ 


$$
\text { H1a: } m_{\text {Diff (post-pre) }}>0
$$

The second hypothesis about the difference between the delivery formats of Entertaining (E) versus Factual (F) videos states:

$\mathrm{H} 2 \mathrm{o}$ : There is no difference in the mean difference scores between the entertaining treatment group and the factual treatment group

$\mathrm{H} 2 \mathrm{a}$ : The mean difference in the entertaining video post-test score minus pre-test score is not the same as the mean difference in the factual video post-test minus pre-test score

$$
\begin{aligned}
& \text { Or } \\
& \text { H2o: } m_{E \text { Diff (post-pre) }}=m_{F \text { Diff (post-pre) }} \\
& \text { H2a: } m_{E \text { Diff (post-pre) }} \neq \mathrm{m}_{\mathrm{F} \text { Diff (post-pre) }}
\end{aligned}
$$

Participants received a link to one of two online surveys delivered by Qualtrics. Qualtrics (www.qualtrics.com) is an online survey vehicle available to academic departments conducting research at the University of North Texas. Using Qualtrics, the researcher created custom surveys that were available to participants electronically, via a link embedded in an email to the participant. Respondents took the survey at a time and location convenient to them during a specified seven-day period. In order to preserve participant anonymity and to separate participant responses from collection of their names for extra credit awards, at the completion of the safe sex survey participants clicked a link to a separate survey instrument, where a single question asked for their name and Enterprise User ID (EUID).

The investigator created two identical Qualtrics surveys. (A copy of the safe sex survey questions appears in the Appendix.) Both Survey A (for group A) and Survey B (for group B) collected demographic information (sex, age, race, educational level) and asked the participants if they knew what the term "safe sex" meant. Participants were asked if they had received sex education in the past, and if so, where and from whom. Participants were asked to document their relationship status (single, dating, in a committed relationship, married) and were given an identical pretest to evaluate their current knowledge about safe sex. Next, participants viewed one YouTube video that the investigator embedded in the survey and which the participant could only view one time. Survey A had the entertaining video showing the older dating couple embedded, and Survey $\mathrm{B}$ had the factual presentation by the physician embedded. Participants were retested using the same test given prior to watching the videos to evaluate knowledge acquired from viewing each type of video. Both surveys concluded with a single open-ended question asking for comments about video presentation style, value of information presented, and thoughts about finding educational content on YouTube. The investigator compared pre- and post-test scores for all participants using a paired t-test to evaluate whether YouTube proved with statistical significance to be a viable health education-informing channel. Pre- and post-test scores for participants viewing the entertaining video were compared to the same scores of the participants that viewed the factual video using a paired t-test to determine if a statistically significant difference in pre- and post-test scores existed between participants in each treatment group.

\section{Research Findings/Results}

Overall, 33 study participants were recruited and 33 responses were received, Fifteen respondents (group A) had taken Survey A and eighteen respondents (group B) had taken Survey B. At the conclusion of the survey period, the investigator reviewed participant data and removed three participants from each group of respondents. Among the participants that took survey A, the investigator removed one participant because he was older than the target age range. The investigator 
removed two participants for providing conflicting answers, such as identical answers to all questions, which invalidates the data that they provided. The investigator removed three respondents to Survey B for similar data issues. One respondent was older than the targeted age range and two provided unreliable answers such as identical answers to all questions. After cleaning the data, 27 usable responses remained (12 for Survey A and 15 for Survey B).

An examination of study sample demographics revealed the following. In providing demographics, total population statistics in each demographic category is followed by a statistic in parentheses showing the demographic for participants that viewed the factual (F) video, and those that viewed the entertaining (E) video. Of the 27 participants that took both surveys (15F, 12E), 14 were female $(6 \mathrm{~F}, 8 \mathrm{E})$ and 13 were male $(9 \mathrm{~F}, 4 \mathrm{E})$, providing a relatively even gender distribution among the respondents. Three participants were between the ages of 18 and 20 (1F, 2E), and twenty-four participants were between the ages of 21 and 24 (14F, 10E). Twenty-six participants were undergraduates $(14 \mathrm{~F}, 12 \mathrm{E})$ and one participant identified himself or herself as a graduate student $(1 \mathrm{~F})$. The racial distribution of the participants was broad, and showed that 2 were African American (1F, 1E), 8 were Asian (4F, 4E), 13 were Caucasian $(8 \mathrm{~F}, 5 \mathrm{E})$ and 4 were Hispanic $(2 \mathrm{~F}, 2 \mathrm{E})$. In terms of relationship status, 14 participants reported that they were single $(6 \mathrm{~F}, 8 \mathrm{E}), 4$ were in a committed relationship $(2 \mathrm{~F}, 2 \mathrm{E}), 6$ were dating $(4 \mathrm{~F}, 2 \mathrm{E})$ and 3 were married $(3 \mathrm{~F}, 0 \mathrm{E})$. Twenty-two participants claimed to have received sex education in the past $(11 \mathrm{~F}, 11 \mathrm{E})$, while 5 had not $(4 \mathrm{~F}, 1 \mathrm{E})$. Of those that had received prior sex education, family members taught four $(3 \mathrm{~F}, 1 \mathrm{E}), 14$ received training in school $(7 \mathrm{~F} .7 \mathrm{E})$, one was self-taught $(1 \mathrm{~F})$, and three received sex education from an unidentified source (3E). Five participants claimed to have received no prior sex education $(4 \mathrm{~F}, 1 \mathrm{E})$. Interestingly, all participants claimed to understand what the term "safe sex" meant.

Participants completed the designated survey and the instructor collected the data. It is important to compare overall pretest and posttest results to determine whether YouTube is an effective health education-informing channel. Then, the comparison of pre- and post-test results between the participants that viewed the entertaining video versus those that viewed the factual video will be used to determine if one message delivery style (factual vs. entertaining) is more effective than the other in facilitating participant knowledge acquisition. Finally, it is important to explore participant perceptions about each video type and to examine the differences in their perceptions about the reliability of health information found on YouTube.

First, to test Hypothesis 1, the investigator conducted a paired t-test (Rosner, 2011) to evaluate whether YouTube was a viable health education-informing channel. The statistically significant results support the contention that YouTube is a viable informing channel for providing safe sex education.

The paired t-test resulted in a $t$ calculated (3.35) that is greater than $t$ critical (1.70) and a p value of 0.0012, which was less than the alpha of 0.05. Therefore, we reject the null hypothesis 1 at the $5 \%$ level of significance and have statistically significant results to support the contention that YouTube is an effective health education-informing channel.

This result was also examined for each sample, factual versus entertaining, and Table 1 again shows a significant difference in the post-test score versus the pre-test score for each treatment group. 


\begin{tabular}{|l|l|l|l|l|l|l|}
\hline \multicolumn{7}{|c|}{ Table 1: t-Test: Paired Two Sample for Means } \\
\hline & $\begin{array}{l}\text { Post- test } \\
\text { Score }\end{array}$ & $\begin{array}{l}\text { Pre-test } \\
\text { Score }\end{array}$ & $\begin{array}{l}\text { Factual } \\
\text { Post test } \\
\text { Score }\end{array}$ & $\begin{array}{l}\text { Factual Pre- } \\
\text { test Score }\end{array}$ & $\begin{array}{l}\text { Entertaining } \\
\text { Post-test Score }\end{array}$ & $\begin{array}{l}\text { Entertaining } \\
\text { Pre-test Score }\end{array}$ \\
\hline Mean & 13.81 & 11.96 & 14.6 & 12.53 & 12.83 & 11.25 \\
\hline Variance & 18.39 & 14.34 & 20.69 & 16.84 & 15.24 & 11.48 \\
\hline Observations & 27 & 27 & 15 & 15 & 12 & 12 \\
\hline $\begin{array}{l}\text { Pearson Correla- } \\
\text { tion }\end{array}$ & 0.755 & & 0.70 & & 0.821 & \\
\hline $\begin{array}{l}\text { Hypothesized } \\
\text { Mean Difference }\end{array}$ & 0 & & 0 & & 0 & \\
\hline df & 26 & & 14 & & 11 & \\
\hline $\mathrm{t}$ calculated & 3.359 & & 2.391 & & 2.455 & \\
\hline $\mathrm{P}(\mathrm{T}<=\mathrm{t})$ one-tail & 0.0012 & & 0.0157 & & 0.0160 & \\
\hline $\mathrm{t}$ Critical one-tail & 1.706 & & 1.761 & & 1.796 & \\
\hline
\end{tabular}

Next, to test Hypothesis 2, the investigator conducted a two-tailed t-test (Rosner, 2011) to evaluate whether the two video formats were different in their ability to facilitate knowledge acquisition in participants. The test compared the mean differences between the pre-test and post-test scores for each treatment group, and the results are shown in Table 2.

\begin{tabular}{|l|r|r|}
\hline \multicolumn{3}{|c|}{ Table 2: } \\
\hline & $\begin{array}{c}\text { Factual Video } \\
\text { Difference }\end{array}$ & $\begin{array}{c}\text { Entertaining } \\
\text { Video Differ- } \\
\text { ence }\end{array}$ \\
\hline Mean & 2.066666667 & 1.583333333 \\
\hline Variance & 11.20952381 & 4.992424242 \\
\hline Observations & 15 & \\
\hline Pooled Variance & 8.474 & \\
\hline $\begin{array}{l}\text { Hypothesized Mean Differ- } \\
\text { ence }\end{array}$ & 0 & \\
\hline Df & 25 & \\
\hline t calculated & 0.428703361 & \\
\hline P(T<=t) two-tail & 0.671810519 & \\
\hline$t$ Critical two-tail & 2.059538553 & \\
\hline
\end{tabular}

The $t$-test resulted in a $t$ calculated (0.42) that is less than $t$ critical (2.05) and a p value of 0.672 that was more than the alpha of 0.05 . Therefore, the investigator failed to reject the null hypothesis 2. Therefore, for Hypothesis 2, the mean difference of the difference in test scores in both treatment groups is not statistically significant, indicating that no significant difference exists in the ability of the videos to facilitate knowledge acquisition for participants and suggesting that message presentation style was not a significant factor in knowledge acquisition.

However, in order for health educators to capitalize on YouTube as a health education-informing channel, it is important to explore participant perceptions about the two message presentation 
styles, their planned behavioral intention, and their thoughts about the likelihood of finding reliable health information on YouTube.

Participants in both groups, after watching their video, rated their feelings about being able to find reliable health information on YouTube. The percentage of responses in each response category for both study groups are in Table 3 below. Table 3 shows that $67 \%$ of participants in Group A (12), who viewed the entertaining video, agreed at some level (Slightly Agree 33\% plus Agree $17 \%$ plus Strongly Agree 17\%) that they could find reliable health information on YouTube. In Group B, who viewed the factual video, 60\% agreed at some level (Slightly Agree 13.33\% plus Agree $40 \%$ plus Strongly Agree 6.67\%) that they could find reliable health information on YouTube. Greater doubt or disagreement was present in Group B (factual video) with $40 \%$ neutral or with some level of disagreement than in Group A (entertaining video) which had 33\% neutral or with some level of disagreement. Still, in the total combined sample, over $59 \%$ of the 27 participants slightly agreed, agreed or strongly agreed they could find reliable health information on YouTube. This suggests to health educators that YouTube is a viable health education-informing channel for this age group.

\begin{tabular}{|c|c|c|}
\hline \multirow{2}{*}{ Question: I feel that I can find reliable health information on YouTube. } \\
\hline Response & \multicolumn{2}{|c|}{ Participant Group } \\
\hline & Group A & Group B \\
& (entertaining video) & (factual video) \\
\hline Strongly Disagree & 0 & $6.67 \%$ \\
\hline Disagree & 0 & $6.67 \%$ \\
\hline Slightly Disagree & $25 \%$ & $13.33 \%$ \\
\hline Neutral & $8 \%$ & $13.33 \%$ \\
\hline Slightly Agree & $33 \%$ & $13.33 \%$ \\
\hline Agree & $17 \%$ & $40 \%$ \\
\hline Strongly Agree & $17 \%$ & $6.67 \%$ \\
\hline
\end{tabular}

Participant criteria for determining the reliability of health information presented on YouTube is further detailed in Table 4. Participants in both groups selected from a series of choices the statements that best reflect the way that they determine if health information that they find on YouTube is accurate. The number of responses in each category for all 27 participants is shown in Table 4 below, and the number of responses in each category for each treatment group is also shown. Participants selected as many of the possible choices as they felt were applicable.

Table 4 shows that the participants in both groups value information presented by a medical professional $(13 \mathrm{~F}, 9 \mathrm{E})$ in a serious $(6 \mathrm{~F}, 6 \mathrm{E})$ and professional tone $(4 \mathrm{~F}, 8 \mathrm{E})$ The information in Video A (entertaining video) had no evidence of a medical professional's input and was somewhat comedic. A physician identified as a member of a premier and well-revered medical institution presented the information in Video B (factual video) in a serious manner. The presence of a medical professional was mentioned as important more often by those that viewed the factual video, whereas more of the participants that viewed the entertaining video were concerned with the number of views that a video had or whether or not a friend felt that the information given was accurate, 
Table 4

Question: I think that I know how to determine if health information that I find on YouTube is accurate. I would consider the following in making that decision (mark all that apply)

\begin{tabular}{|c|c|c|c|}
\hline Response & $\begin{array}{c}\text { Number of Times } \\
\text { Selected }\end{array}$ & $\begin{array}{c}\text { Number of } \\
\text { Times Selected } \\
\text { (factual) }\end{array}$ & $\begin{array}{c}\text { Number of } \\
\text { Times Selected } \\
\text { (entertaining) }\end{array}$ \\
\hline $\begin{array}{c}\text { How popular (how many views) a } \\
\text { video has }\end{array}$ & 9 & 3 & 6 \\
\hline $\begin{array}{c}\text { Whether a medical professional cre- } \\
\text { ated or presents the information }\end{array}$ & 22 & 6 & 6 \\
\hline $\begin{array}{c}\text { Whether the tone of the video is se- } \\
\text { rious }\end{array}$ & 12 & 4 & 8 \\
\hline $\begin{array}{c}\text { Whether the tone of the video is pro- } \\
\text { fessional }\end{array}$ & 12 & 0 & 4 \\
\hline $\begin{array}{c}\text { Whether a friend that I trust thinks it } \\
\text { is accurate }\end{array}$ & 4 & 1 & 6 \\
\hline $\begin{array}{c}\text { If the video was professionally made } \\
\text { or homemade }\end{array}$ & 7 & & 6 \\
\hline
\end{tabular}

The survey asked participants, after watching the video, about how the video would affect their safe sex behavior in the future. The impact on potential behavior change of the safe sex education provided was substantial. First, $85 \%$ (23/27) of the respondents indicated that because of watching the video, they intended to ask a new sexual partner about their sexual history before having sex the first time. Additionally, 89\% (24/27) of the participants indicated that they felt that it is important to test regularly for STDs, and 96\% (26/27) of the participants indicated that it is important to ask their partners if he or she tested regularly for STDs. Another large portion of participants $93 \%$ (25/27) indicated that they planned to discuss condom use with any new sexual partners, and an identical group (25/27 or $93 \%)$ of participants felt that they could suggest condom use to a new sexual partner. Finally, 64\% (16/27) of the participants reported that they were likely to change their current behavior because of watching the video, The Fisher exact likelihood test (Siegel \& Castellan, 1988) shows that all these proportions excluding the behavior change proportion (16/27) are statistically significant despite the small samples involved. These findings further support the potential impact of YouTube as a health-informing channel.

Participants' open-ended comments, collected at the end of the survey, further elaborate. The survey asked participants in both groups the following question: "In your own words, please describe your thoughts about the video that you watched. Provide information about the video presentation style, the value of the content to you and your opinion about finding this information on YouTube."

Participants in Group A (12), who viewed the entertaining video, gave the following responses, several of which indicate a preference for a more serious presentation of health information:

"It was very helpful in helping young adults be informed about safe sex".

"I thought it was informative".

"I found this video very helpful with some sexual information I didn't know. Already new STDs are a serious concern of mine but after this video it has made it clear that there are certain methods of further preventing STDs. Talking to your partner is key when it 
comes to sexual information. Video overall was good and provided lots of serious information."

"I didn't like the fact that it was presented (demonstrated) by older people. The info that was given was professional and seemed accurate. The presentation style was great, excluding the people used. Possibly more visuals would help."

"I thought the video had decent information but it was not shown so well. It was kind of a joke with 2 old people smiling and playing with a teapot with a crochet cap. The information was good about dental dams and anal and how Al Capone died of syphilis, but I felt the demonstrations should have been more realistic if they want people to actually go through with these safe sex methods. I liked the info but I wouldn't take the video as seriously just cause the video showed two old people fooling around with a teapot and crochet cap. I kinda laughed at their actions."

Another interesting perspective from Group A was:

"The video was good. It provided decent information and tips while also further provoking the viewer to abstain from sex by putting the mental image of the older couple possibly getting it on, while also providing a comical scenario with the old couple. I think by using the older couple viewers will pay more attention. When I was in school the video we had to watch had kids our age or actors pretending to be our age, by making the video to relate to us. The viewers (young high school students) who already feel like the world doesn't understand us) were less inclined to a) take the video seriously and b) listen. It grabbed my attention and I am sure it will help educate someone who hasn't heard this information before."

Participants in Group B (15), who viewed the factual video, offered the following:

"The video seemed to be told by a professional health worker of some sort and it looks to be made for educational purposes. The content of the video was mostly unnew to me but the information given was important all the same."

"About educating people about STDs and how to prevent them and practice safe sex. I feel that you can't trust any medical information you get from YouTube because it hasn't been evaluated by a doctor."

"Very informative and to the point on safe sex practices. I like how it was presented and the information that was given."

"Professional; serious but informative; interesting use of graphics to better demonstrate the topics."

"It was informative. However, I wasn't expecting this for the survey!"

"I am really happy for having seen this video. I think that this video helps understand the impact of different diseases that we could contract. It helps us be careful about ourselves in a relationship."

"It was a well-made video and I totally agree that everyone should pay attention to this because it is not something to play around with. We are talking about how to prevent STDs and prevent causes of death."

"Actually somewhat entertaining"

"The video was interesting. I had never heard of the use of female condoms before. The way the video showed diagrams to explain how different things worked was very helpful." 
"The video was well made and the narrator did a good job of articulating the most key points of sexual education."

"It was very informational. It's not uncommon to find reliable sources on YouTube but it would always be wise to consult a health professional."

Comments from both groups of participants suggest a willingness to receive health information from YouTube. In general, participants value video presentations that are "interesting" and "attention grabbing", yet "serious". Participants also claimed to appreciate illustrations or diagrams that clarified key points. The presence of a health care professional (such as the MD) in Video B seemed to add credibility to the information presented and to help viewers to focus and subsequently articulate the serious consequences of not following safe sex practices. The information shown in Table 4 supports the claim that those that watched the factual video had a preference for information presented by a clinical professional in a serious manner. Table 4 also shows that those that watched the entertaining video preferred to rely on subjective measures, like video popularity, as measured by the number of recorded viewings for the video. Table 4 further shows that those that watched the entertaining video valued their friends' assessments of the accuracy of the information presented, which was not an important criterion for those that watched the factual video.

\section{Practical Implications}

This study provides statistically significant evidence that YouTube is a viable health educationinforming channel capable of facilitating knowledge acquisition for users in this age group. The study also supports the contention that YouTube can facilitate behavior change regardless of the type of message appeal (entertaining or factual) presented. This significant finding enhances the growing awareness of the power of this social media venue for the informer to educate and inform in the healthcare arena.

In addition, the study has provided a framework of user preferences for health education messaging on YouTube. While users in both groups acquired important knowledge about safe sex practices, and many indicated that they planned to change their future behavior, distinct message preferences emerged. Users prefer health education messages presented by a medical professional, to have a serious and professional tone and yet be engaging, as well as including diagrams or other visual tools to enhance understanding. While no one message delivery style will work for all users, future work will define further the use of this popular and important informing channel by health educators. While there is no evidence to suggest any difference in the positive educational impact of videos with distinctly different message delivery styles, future work can clarify the user characteristics or content that make a particular message delivery style successful for specific user populations.

\section{Study Limitations}

This work has several limitations. The use of a small sample of college students limits the ability to apply the study results to the general population of users in this age group, particularly those affected by the Digital Divide or economic factors that may prevent them from accessing online health education via YouTube. Despite these limitations, college students represent an important population for whom this health risk management information is relevant. While the small sample size is a limitation, the investigator would not expect the statistical significance of the results in Table 1 to change if the sample were larger. The investigator also would not expect the lack of statistical significance in Table 2 to change because both results were relatively extreme. However, a larger sample size would be likely to improve the counts in some of the response categories shown in Table 4. In addition, another limitation in this work is that the sensitive and direct 
nature of the content of these videos is potentially distracting to some viewers, and may affect their ability to learn or retain new information.

\section{Conclusions}

This work advances knowledge about the use of YouTube as an effective health educationinforming channel for a specific user demographic. In this study, YouTube health education messages, both factual and entertaining, resulted in a statistically significant improvement in knowledge of safe sex practices and STD prevention for all participants. Health educators recognize that YouTube is a favored social venue for users in this age group. Because of this work, health educators can take advantage of existing user behaviors to promote improved sexual behavior decision-making and a reduction in the incidence of STDs for vulnerable 18-24 year olds. This study confirms both YouTube's health education utility and its ability to serve as a health education-informing channel. Because of these contributions, this study also extends the informing science framework to health information delivery.

\section{Appendix}

\section{Safe Sex Survey Questions}

Indicate your gender

Indicate your age

Indicate your academic level

Indicate your race

Indicate your relationship status

I know what the phrase 'safe sex' means

I have received safe sex education in the past

If you answered no to the last question, skip to the next section. If you answered yes to the previous question, please indicate where you received education about safe sex

The following section will assess your current knowledge about safe sex practices

I think that safe sex only refers to preventing pregnancy

Sexually transmitted diseases (STD's) are something that I am concerned about

Sexually transmitted diseases are visible to the eye if your partner has one

I consider sexual abstinence to be a realistic way of preventing STD's

To prevent an STD I must have sex only with a partner that is not infected

People are honest when they talk about sex

The most important first step in preventing STD's is to limit the number of sexual partners that you have

Everyone should be tested for STD's on a regular basis

Condoms are only made for males

The goal of using a condom is to prevent contact with your partner's bodily fluids

Oral sex is a safe way to prevent STD's

Condoms, if removed carefully from the package, are safe to use

Condoms should be put on the male before sexual intercourse begins, just to be safe 
Condoms should fit tightly around the penis to be effective

Condoms are good for a long time as long as the package is intact

Female condoms are as effective as male condoms

If a woman uses a female condom, she can remove it properly after she stands up after having sex

A man can remove a condom properly after sex by simply pulling it off

An oil-based lubricant like Vaseline can reduce tearing of both the skin and the condom

All condoms are made of latex

Oral barriers (dental dams) are not necessary when the man is wearing a condom

You should explore your partner's sexual history before having sex the first time

You don't have to be concerned about your partner's sexual history if you know your partner well.

When is it important to ask if your partner has been tested or treated for an STD?

In the next segment, you will watch a YouTube video about safe sex. The video is currently available on YouTube. Please watch the video embedded below. Do not download the video. Start the video by clicking the right arrow $(>)$ in the gray bar beneath the video. Do not advance to the next screen until after you have watched the video. You will not be able to return to it.

\section{VIDEO EMBEDDED HERE}

Now that you have watched the video, please answer the following questions based on information that was provided in the video. You will not be able to return to the video. Simply answer the questions based on what you remember from watching the video.

I think that safe sex only refers to preventing pregnancy

Sexually transmitted diseases (STD's) are something that I am concerned about

Sexually transmitted diseases are visible to the eye if your partner has one

I consider sexual abstinence to be a realistic way of preventing STD's

To prevent an STD I must have sex only with a partner that is not infected

People are honest when they talk about sex

The most important first step in preventing STD's is to limit the number of sexual partners that you have

Everyone should be tested for STD's on a regular basis

Condoms are only made for males

The goal of using a condom is to prevent contact with your partner's bodily fluids

Oral sex is a safe way to prevent STD's

Condoms, if removed carefully from the package, are safe to use

Condoms should be put on the male before sexual intercourse begins, just to be safe

Condoms should fit tightly around the penis to be effective

Condoms are good for a long time as long as the package is intact

Female condoms are as effective as male condoms

If a woman uses a female condom, she can remove it properly after she stands up after having sex

A man can remove a condom properly after sex by simply pulling it off 
An oil-based lubricant like Vaseline can reduce tearing of both the skin and the condom All condoms are made of latex

Oral barriers (dental dams) are not necessary when the man is wearing a condom You should explore your partner's sexual history before having sex the first time You don't have to be concerned about your partner's sexual history if you know your partner well

When is it important to ask if your partner has been tested or treated for an STD?

The section below asks about your thoughts after watching the video

After watching the video I will ask a new sexual partner about their sexual history before having sex

I feel that it is important to be tested regularly for STD's

I feel that it is important to ask my partner if he or she has been treated for STD's

I plan to discuss condom use with any new sexual partner that I have

I feel that I could suggest condom use to a new sexual partner

I am likely to change my behavior as a result of watching this video

I feel that I can find reliable health information on YouTube

I think I know how to determine if health information that I find on YouTube is accurate

In your own words, please describe your thoughts about the video that you watched, Provide information about the video presentation style, the value of the content to you, and your opinion about finding this information on YouTube.

\section{References}

Abrahamson, J. A., Fisher, K. E., Turner, A. G., Durrance, J. C., \& Turner, T. C. (2008). Lay information mediary behavior uncovered: Exploring how nonprofessionals seek health information for themselves and others online. Journal of the Medical Library Association, 96, 310-323.

Alexa. (2011). About You Tube. Retrieved March 28, 2011 from http://www.alexa.com/siteinfo/youtube.com\#

Arroyave, J. (2008). Testing the effectiveness of an entertainment-education health-focused soap opera: Exposure and post-discussion in Colombian young adults. Investigación y Desarrollo, 16(2), 232-261.

Bargh, J. A., \& McKenna, K. Y. A. (2004). The internet and social life. Annual Review of Psychology, 55, 573-590.

Baumann, M. (2010). Pew internet: Highlights of the digital domain. Information Today, 27(4), 13.

Boyd, D. M., \& Ellison, N. B. (2007). Social network sites: Definition, history, and scholarship. Journal of Computer-Mediated Communication, 13(1), 210-230. doi:10.1111/j.1083-6101.2007.00393.x

Brashers, D. E., Goldsmith, D. J., \& Hsieh, E. (2002). Information seeking and avoiding in health contexts. Human Communication Research, 28, 258-271.

Buzzetto-More, N.A. (2012). Social networking in undergraduate education. Interdisciplinary Journal of Information, Knowledge, and Management. Special Section on Social Networking, Teaching and Learning, 7, 63-90. Retrieved from http://www.ijikm.org/Volume7/IJIKMv7p063-090Buzzetto611.pdf

Centers for Disease Control and Prevention (2010). Sexually transmitted disease surveillance, 2010. Retrieved November 21, 2012 from: http://www.cdc.gov/std/stats10/trends.htm 
Centers for Disease Control and Prevention. (2011). The health communicator's social media toolkit. Retrieved March 24, 2012, from: http://www.cdc.gov/SocialMedia/Tools/guidelines/

Choi, S. M., Kim, Y., Sung, Y., \& Sohn, D. (2011). Bridging or bonding? A cross-cultural study of social relationships in social networking sites. Information, Communication \& Society, 14, 107-129. doi:10.1080/13691181003792624

Chou, W. S., Hunt, Y. M., Beckjord, E. B., Moser, R. P., \& Hesse, B. W. (2009). Social media use in the United States: Implications for health communication. Journal of Medical Internet Research, 11(4), e48.

Cline, R. J., \& Haynes, K. M. (2001). Consumer health information seeking on the internet: The state of the art. Health Education Research, 16(6), 671-692.

Cohen, E. B. (2009). A philosophy of informing science. Informing Science: the International Journal of an Emerging Transdiscipline, 12, 1-15.

Dawson, A. L., Hamstra, A. A., Huff, L. S., Gamble, R. G., Howe, W., Kane, I., \& Dellavalle, R. P. (2011). Online videos to promote sun safety: Results of a contest. Dermatology Reports, 3(1), 17-19. doi:10.4081/dr.2011.e9

Greenwood, B. (2009). Pew reports: Internet age barrier vanishing. Information Today, 26(5), 2-11.

Hardin, G., Ryan, S., \& Prybutok, V. (2012). Social networking site continuance: The paradox of negative consequences and positive growth. Informing Science: the International Journal of an Emerging Transdiscipline, 15, 207-227.

Hordemann, G., \& Chao, J. (2012). Design and implementation challenges to an interactive social media based learning environment. Interdisciplinary Journal of Information, Knowledge, and Management. Special Section on Social Networking, Teaching and Learning, 7, 91-107. Retrieved from http://www.ijikm.org/Volume7/IJIKMv7p091-107Hordemann610.pdf

Jin, B. (2006). Viewing factors in public health entertainment-education programing. Journal of the Northwest Communication Association, 35, 79-94.

Jones, S., \& Fox, S. (2009). Generations online in 2009: In Pew Internet and American life project. Retrieved March 1, 2011 from http://www.pewinternet.org/Reports/2009/Generations-Online-in2009.aspx

Kahn, J. (2008). The wisdom of patients: Health care meets online social media. Medical Benefits, 25(13), 12 .

Keelan, J., Pavri-Garcia, V., Tomlinson, G., \& Wilson, K. (2007). YouTube as a source of information on immunization: A content analysis. JAMA: The Journal of the American Medical Association, 298(21), 2482-2484.

Liu, Y. (2010). Social media tools as a learning resource. Journal of Educational Technology Development and Exchange, 3(1), 101-114.

Lopez-Fernandez, O., \& Molina-Azorin, J. (2011). The use of mixed methods research in the field of behavioral sciences. Quality \& Quantity, 45(6), 1459-1472. doi: 10.1007/s11135-011-9543-9

Luo, J. S. (2008). Patient education in the Internet age. Primary Psychiatry, 15(4), 24-26.

Luo, L. (2010). Social networking websites: An exploratory study of student peer socializing in an online LIS program. Journal of Education for Library \& Information Science, 51(2), 86-102.

Madden, M. (2010). Older adults and social media. Retrieved from Pew Internet and American Life Project: http://pewinternet.org/Reports/2010/Older-Adults-and-Social-Media.aspx

Moyer-Guse, E., Mahood, C., \& Brookes, S. (2011). Entertainment-Education in the context of humor: Effects on safer sex intentions and risk perceptions. Health Communications, 26 (8), 765-774. doi: $10.1080 / 10410236.2011 .566832$ 
Paek, H., Kim, K., \& Hove, T. (2010). Content analysis of antismoking videos on YouTube: Message sensation value, message appeals, and their relationships with viewer responses. Health Education Research, 25(6), 1085-1099.

Pew Internet and American Life Project. (May, 2010). Tracking survey. Retrieved March 23, 2012 from http://www.pewinternet.org/Trend-Data-(Adults)/Whos-Online.aspx

Pew Internet and American Life Project. (n.d.). About us. Retrieved March 28, 2011 from http://www.pewinternet.org/About-Us.aspx

Rajapat, V. (2009). Social media: Trends \& growth of digital media. Siliconindia, 12(6), 28-30.

Reynolds, B.J. (2010). Building trust through social media. CDC's experience during the H1N1 influenza response. Marketing Health Services, 30(2), 18-21.

Rogers, E. M. (1995). Diffusion of innovations (4th ed). New York: Free Press.

Rosner, B. (2011). Fundamentals of Biostatistics (7th ed). Boston: Brooks Cole, Cengage Learning.

Scale, M. (2008). Facebook as a social search engine and the implications for libraries in the twenty-first century. Library Hi Tech, 26(4), 540-556

Siegel, S., \& Castellan, N.J. (1988). Nonparametric statistics for the behavioral sciences (2nd ed.). McGraw-Hill: New York.

Singhai, A., \& Rogers, E. (2002). A theoretical agenda for entertainment-education. Communication Theory. 12(2), 117-135. doi: 10.1111/j.1468-2885.2002.tb00262.x

Smith, S. W., Nazione, S., LaPlante, C., Kotowski, M. R., Atkin, C., Skubisz, C. M., \& Stohl, C. (2009). Topics and sources of memorable breast cancer messages and their impact on prevention and detection behaviors. Journal of Health Communication, 14(3), 293-307. doi:10.1080/10810730902805903

Suggs, L. S. (2006). A 10-year retrospective of research in new technologies for health communication. Journal of Health Communication, 11(1), 61-74. doi:10.1080/10810730500461083

Valencia, M., Kingston, N., Nakamura, R., Rosenfield, F., \& Schwartz, M. (2004). The evolution of health education: The Kaiser Permanente Southern California experience. Health Promotion Practice, 5, 2027.

Weaver, J. B., Thompson, N. J., Weaver, S. S., \& Hopkins, G. L. (2009). Healthcare non-adherence decisions and internet health information. Computers in Human Behavior, 25(6), 1373-1380. doi:10.1016/j.chb.2009.05.011

Yu, J. (2010). Sex education beyond school: Implications for practice and research. Sex Education, 10(2), 187-199. doi: 10.1080/14681811003666515

\section{Biography}

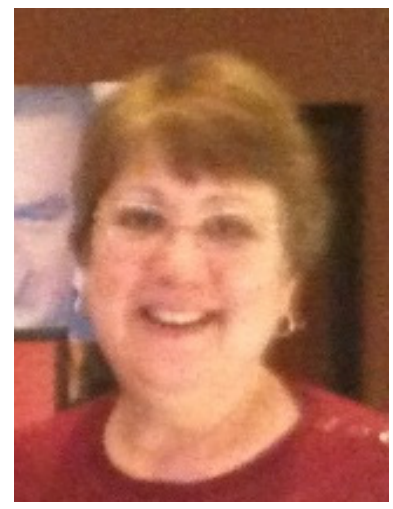

Gayle L. Prybutok is currently pursuing her $\mathrm{PhD}$ in information science with a specialization in health informatics at the University of North Texas. Gayle has over 30 years of experience as a nurse and health care executive in a variety of ambulatory care and hospital settings. Her research interests include the use of social media to communicate important health information to target populations, and the information seeking behaviors of specific populations in their quest for health information. 